\title{
Book Review by Jon C. Schommer, Ph.D., Editor, INNOVATIONS in pharmacy
}

\author{
The Good Pharmacist - Book 2: Enhancing Pharmacy as a True, Clinical and Paid Profession \\ William N. Kelly and Elliott M. Sogol \\ William N. Kelly Consulting and Publishing, Inc. \\ East Clearwater, FL
}

\section{http://www.thegoodpharmacist.com/}

wkelly@health.usf.edu

emsogol@gmail.com

The Good Pharmacist, Book II, Enhancing Pharmacy as a True, Clinical and Paid Profession is the second book in a series where Book I focuses on the characteristics of a good pharmacist and Book II offers insight for how the profession of pharmacy can transform into a fully clinical and paid profession. Kelly and Sogol bring years of experience and expertise to these books. They present their ideas in a straightforward and unapologetic manner and the writing style is purposely provocative. The books are designed with student pharmacists and practicing pharmacists in mind. Readers are challenged to contemplate what impact they are having in their work. Although the primary audience is mostly student pharmacists and pharmacists, I wanted to let the readers of this journal know about this book series. Many readers of this journal are scientists, educators, and administrators from around the world. I believe that the way Kelly and Sogol have written these books will generate innovative ideas, engender contemplation, and inspire you. When you read these books, I recommend that you picture a wise person with much experience speaking to you in a no-nonsense manner ... telling you like it is ... and how it could be. You will be glad you listened.

\section{About the authors:}

William N. Kelly has more than 40 years of experience in health care as a pharmacy executive, researcher, professor, and clinician. He has published extensively and has presented his work both nationally and internationally. He is currently president of William N. Kelly Consulting, Inc., a company devoted to advancing medication safety and the practice of pharmacy, and vice president of scientific affairs for Visante, an international health care consulting firm.

Elliott M. Sogol is Senior Vice President, Strategy at Pharmacy Quality Solutions, Inc. He has over 30 years of experience as a healthcare executive and pharmaceutical leader with broad-based academic, professional association, and corporate industry knowledge and experience. Dr. Sogol has expertise in global strategic planning, relationship management, personnel development, project implementation, team leadership and organizational management.
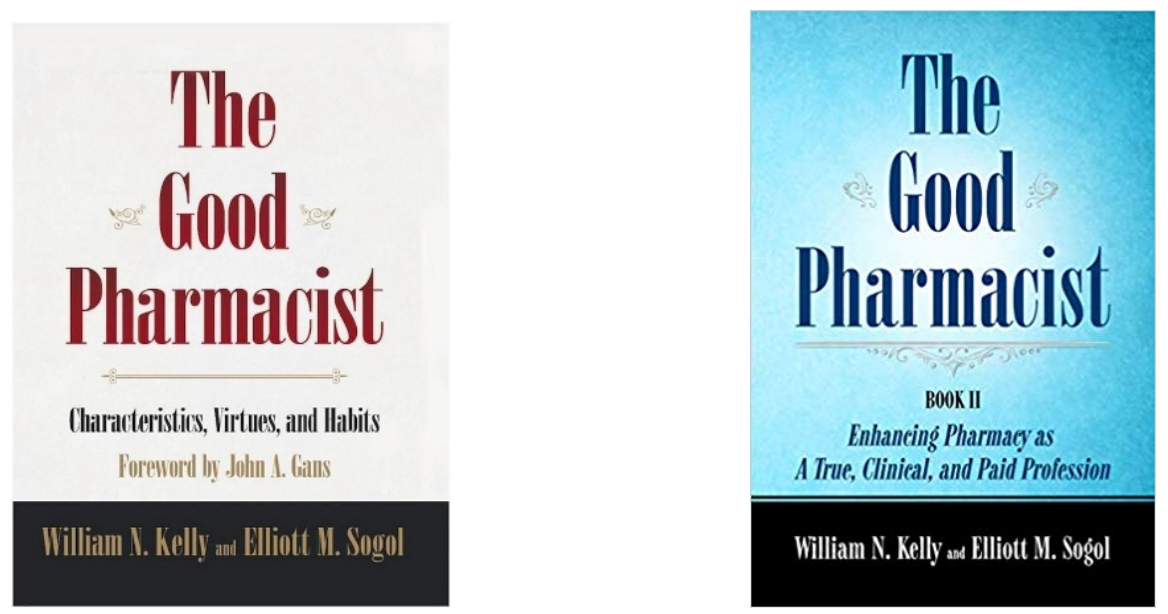